\title{
1 A serial dilution method for assessment of microplastic toxicity in suspension
}

2 Zandra Gerdes, Markus Hermann, Martin Ogonowski and Elena Gorokhova

3 Department of Environmental Science and Analytical Chemistry, Stockholm

4 University, Svante Arrhenius väg 8, SE-11418 Stockholm, Sweden.

\section{TOC}

6

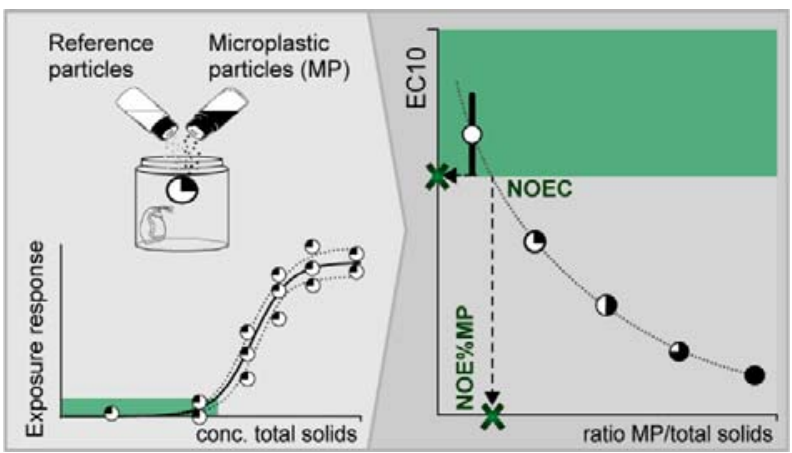




\section{Abstract}

8 The occurrence of microplastic (MP) in the environment is of global concern. MP risk

9 assessment, however, is currently hampered by lacking ecotoxicological methods due

10 to conceptual and practical problems with particle exposure. Natural particles of

11 similar size as MP, e.g., clay and cellulose, occur abundantly in the environment. For

12 MP risk assessment and regulation it must be established whether the addition of MP

13 to these particles represents an additional hazard. We present a novel approach

14 employing a serial dilution of MP and reference particles, in mixtures, which allows

15 the differentiation of MP effects from other particulates. We demonstrate the

16 applicability of the method using an immobilisation test with Daphnia magna

17 exposed to polyethylene terephthalate (MP) and kaolin clay (reference material). In

18 the concentration range of 0.1 to $10000 \mathrm{mg} \mathrm{L}^{-1}$ of total suspended solids (TSS), with

19 MP contributing 0-100 \%, the $\mathrm{LC}_{50}$ values for MP-kaolin mixtures were significantly

20 lower compared to the pure kaolin suspension. MP particles were thus more harmful

21 to daphnids than the reference material. The estimated threshold for \%MP

22 contribution above which higher mortality was observed was $1 \% \mathrm{MP}$ at $36 \mathrm{mg}$ TSS

$23 \mathrm{~L}^{-1}$. This approach has a potential for standardisation of MP ecotoxicological testing

24 as well as other particulate material of anthropogenic origin. 


\section{Introduction}

The increasing environmental pollution with plastic waste is of global concern. What is more, this debris eventually breaks down to small fragments collectively termed microplastics (MP) that are omnipresent in aquatic environments, including alpine lakes, rivers, oceans and arctic ice. ${ }^{1-4}$ The amounts of the plastic debris in general, and MP, in particular, are expected to increase because of increased production, continuous discharge, and fragmentation. ${ }^{5}$ Research on the hazard assessment of solid polymer particulates is in high demand due to public and scientific concerns.

Nevertheless, scientists disagree on the immediacy of the MP pollution problem, ${ }^{6-9}$ and it remains largely unclear whether MP are harmful to biota and what the impact mechanisms are. The continuing uncertainty is, at least partly, related to the fact that MP are a new type of environmental contaminant with yet unsettled methodology for hazard testing.

The first experimental MP effect studies included a wide range of animal species focusing mainly on feeding-related impacts in filter-feeders, such as bivalves ${ }^{10-12}$ and zooplankton ${ }^{13,14}$ Filter-feeders continue to be among the commonly used test organisms in MP effect studies because they are susceptible to MP exposure via ingestion. Since MP particles are nutritionally inert, their ingestion decreases the energy intake. In other words, the ingestion of refractory material and alterations in feeding (a primary response) leads to lower growth and reproduction (secondary responses) as a result of the decreased caloric intake. ${ }^{15}$

All these processes occur not only with MP but also with any other refractory material present in natural seston. Both mineral ${ }^{15-18}$ and $\mathrm{MP}^{13,14,19,20}$ particles have been reported to alter feeding activity and reduce growth. Natural processes, such as wind 
and resuspension, primarily affect the presence of nutritionally inert particles in the water; whereas, human activities, like, dredging and stormwater runoff, may also elevate their concentrations. High concentrations of total suspended solids (TSS) have been found to reduce primary production, ${ }^{21}$ suppress population growth of zooplankton $^{22}$ and alter feeding behaviour in fish. ${ }^{23}$ Therefore, to protect wildlife, water quality standards are implemented for TSS concentrations or allowable TSS levels in, e.g. stormwater effluents, ${ }^{24}$ lakes and streams ${ }^{25}$.

Regulatory efforts to set allowable MP levels are calling for adequate methodological approaches for hazard assessment, relevant model species, and exposure scenarios. A step towards quantifying hazardous properties of synthetic polymer microparticles is to develop and apply standardised practices and experimental designs that will be able to provide threshold values of these effects. However, given the presence of various particulates and the hazardous effects of high TSS concentrations, such designs should include the MP in question together with environmentally relevant reference material(s). Particular attention should be paid to the similarity of basic physical properties that are important for biological responses, e.g., size distribution and shape, between the reference particles and the MP. ${ }^{13,26}$ Also, to maintain the experimental reproducibility and stable encounter rates in a pelagic exposure scenario, it is important that all particles be kept in suspension during the incubation.

A recent comparison of the effects exerted by MP and mineral particulates suggests some similarity in responses across different levels of biological organisation, albeit with an indication of a greater hazard by MP. ${ }^{27}$ Since natural particles are more abundant than MP in aquatic environments, ${ }^{7}$ the hazardous levels of MP should rather be presented as a relative contribution of MP to TSS and not the absolute concentrations. 
74 To date, there is no standard approach for MP effect assessment, ${ }^{28}$ despite a rapidly

75 rising number of reports on MP effects under laboratory conditions. This is partly

76 because it is challenging to design exposure experiments with environmentally

77 relevant concentrations of MP based on the commonly reported levels $(<10$ particles

$\left.78 \mathrm{~m}^{3}\right)^{29-31}$. Moreover, the existing approaches do not explicitly test the effects of MP per

79 se but those of nutrition-free particulates. To move the field of MP ecotoxicology

80 forward, we need to use test methods that (1) are appropriate for delineating effects of

81 different particulate materials in mixtures, (2) provide estimation of the critical

82 concentrations of MP in different environments, (3) allow high-throughput testing,

83 and (4) support read-across and categorical assessment of solid polymer particles.

84 Here, we propose a new approach employing a linear serial dilution of MP and

85 reference particles in mixtures, to identify MP-specific toxicity while controlling for

86 the total concentration of suspended matter in the experimental system. Further, we

87 demonstrate the applicability of this approach using the 96-h exposure of the

88 cladoceran Daphnia magna to a mixture of polyethylene terephthalate (PET) as a test

89 MP and kaolin as a reference particle. 
METHOD

91 The MP Ratio Test was designed to examine whether a particulate material (test particle) is

92 harmful when co-occurring in a mixture with naturally present particulates (reference

93 particle) across a range of TSS concentrations. The rationale is as follows: if the test particle

94 is more harmful than the reference particle, then decreasing its contribution to a mixture with

95 the reference particles should decrease the overall toxicity, assuming additivity of the effects

96 (fig. 1). When the test (MP) and reference (mineral) particles are provided at varying

97 proportions for each TSS concentration, then, by using a range of TSS concentrations, a dose-

98 response relationship can be established for each mixture.
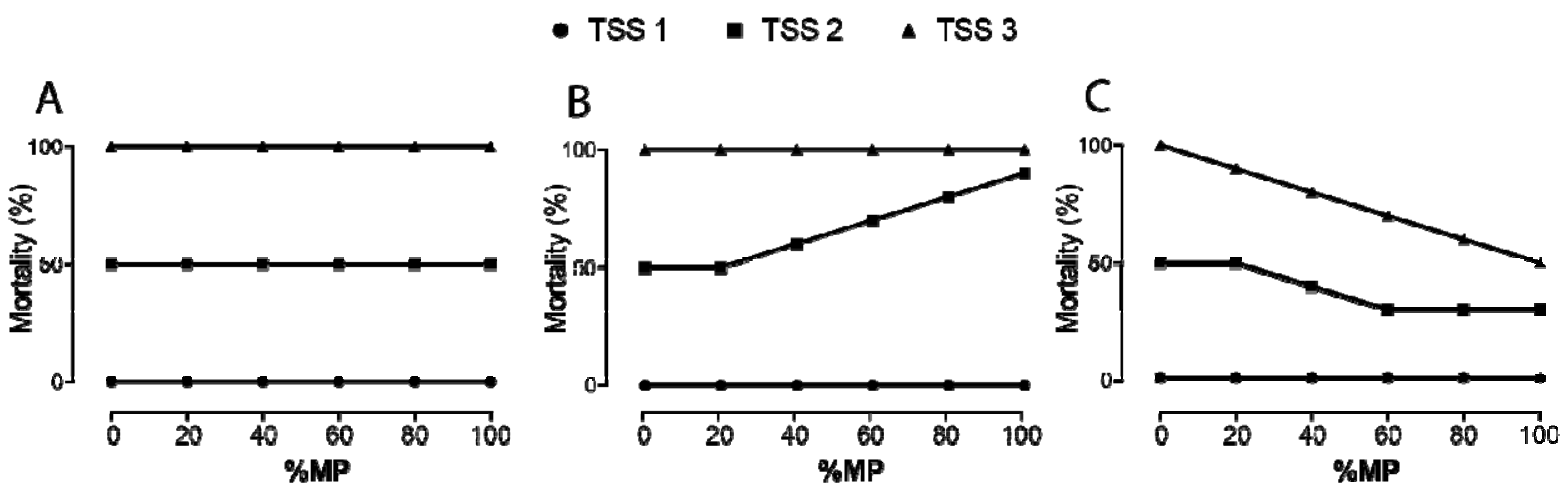

100 Figure 1. Possible outcomes of the MP Ratio Test, shown as a response (in this case

101 Mortality\%) to the relative MP contribution (\%MP) to the TSS in the test system, including

102 three test concentrations of TSS. The TSS concentrations denoted as 1, 2 and 3 represent

103 increasing levels of TSS in the system. Scenario A shows no MP effect because mortality is

104 only responding to the increasing TSS level. Scenario B shows an additive effect of MP

105 because Mortality\% is positively affected \%MP above a critical threshold. Scenario C shows

106 an ameliorating effect of \%MP on TSS toxicity. Based on existing reports for TSS effects on

107 Daphnia, we expect no effect at low TSS concentrations. 
109 Test organism. The freshwater cladoceran Daphnia magna was used as the test species.

110 These microcrustaceans are the most common model organisms in aquatic ecotoxicology and 111 have been used extensively in studies assessing both $\operatorname{TSS}^{13,22,32-34}$ and MP ${ }^{13,33,35}$ effects. All

112 experimental animals originated from the same clone (Clone 5; The Federal Environment

113 Agency, Berlin, Germany) cultured in M7 media at a density $\sim 10$ ind. $\mathrm{L}^{-1}$ and fed ad libitum

114 with a mixture of Pseudokirchneriella subcapitata and Scenedesmus spicatus.

115 The reference and test particles. Kaolin (Sigma-Aldrich) was used as the reference particle;

116 it occurs globally in suspended particulates and has previously been used in tests with

117 daphnids, both as a reference particle when assessing MP effects ${ }^{13}$ and as a test particle when

118 assessing effects of $\mathrm{TSS}^{32}$. As the test MP, we used polyethylene terephthalate (PET

119 Goodfellow), to represent a plastic that is commonly found in the environment. The PET was

120 obtained as 3-5 mm-sized pellets from the manufacturer and milled to a powder by Messer group $\mathrm{GmbH}$, Germany. The powder was first mixed with milliQ water containing $0.01 \%$ v/v of a non-ionic surfactant (Tween 80, Sigma-Aldrich), and sequentially wet-sieved to produce a size fraction similar to that of kaolin (for particle size distributions and details on

124 preparation of the test particles see Fig. S1-2, Supporting Information).

125 Test suspensions. Particle stocks were prepared by suspending weighed kaolin and MP with

126 M7 media (reconstituted lake water) ${ }^{36}$; the volumes were adjusted to produce equal mass-

127 based concentrations $\left(0.1,1,10,100,1000,10000 \mathrm{mg} \mathrm{L}^{-1}\right)$. The test suspensions were

128 prepared in batches with $0 \%, 20 \%, 40 \%, 60 \%, 80 \%$ and $100 \%$ of MP contribution to

129 TSS. These test suspensions were then transferred to 50-mL polypropylene centrifuge tubes

130 and used in the exposure system.

131 Experimental setup and procedures. To demonstrate the application of the MP Ratio Test,

132 we conducted the Daphnia sp. acute immobilisation test (OECD 202), with some 
133 modifications. The standard Daphnia immobilisation test assesses 48-h mortality

134 (immobilisation) in individuals exposed to a range of test concentrations. Based on our pilot

135 experiments with kaolin and the reported data for MP effects on D. magna mortality ${ }^{37}$, we

136 prolonged the test duration to $96 \mathrm{~h}$. Ten daphnids ( $<24 \mathrm{~h}$ old) were placed in each test tube

137 with the exposure media; 24 treatments (\% MP $\times$ TSS concentration) were used with four

138 replicates per treatment and two particle-free controls per run. Three TSS concentrations

139 were tested for the $20-80 \%$ MP mixtures and six concentrations with the single particle

140 exposure. When sealing the test tubes, care was taken to avoid trapping air bubbles inside the

141 tube. The tubes were mounted on a plankton wheel in a thermo-constant room at $21^{\circ} \mathrm{C}$ with a

142 light: dark cycle of $16: 8 \mathrm{~h}$ and the test was terminated after $96 \mathrm{~h}$ by counting live and dead

143 animals. The daphnids were considered dead if they did not move for $30 \mathrm{~s}$ after being

144 agitated.

\section{Statistical analyses}

147 For each mixture, the $\mathrm{LC}_{50}$ values and the corresponding $95 \%$ confidence intervals were

148 calculated using a dose-response curve fitted with three-parameter logistic regression

149 (GraphPad Prism, v. 7.0; GraphPad Software, La Jolla California USA). The median

mortality in the particle-free control was used as the bottom constraint and $\leq 100 \%$ mortality as the top constraint. The $\mathrm{LC}_{50}$ values were compared across the test mixtures to evaluate the effect of $\% \mathrm{MP}$ in the mixture; the non-overlapping confidence intervals were used as evidence of the significant difference between the treatments (\%MP). Further, we estimated

154 the corresponding $\mathrm{LC}_{10}$ values and used them as a surrogate for NOEC. ${ }^{38}$ One-phase 155 exponential decay function was fitted to describe the relationship between the $\mathrm{LC}_{10}$ values and \% MP in the mixture. As NOEC, we used the interpolated $\mathrm{LC}_{10}$ value corresponding to 
157 the lower bound of the $95 \%$-confidence interval for $\mathrm{LC}_{10}$ in pure kaolin. The critical

158 threshold for \%MP in the mixture representing no effect level of \%MP in the test system was

159 termed NOE\%MP (No Effect Percentage of Microplastics).

\section{RESULTS}

162 Survival in the particle-free controls was high (average $95.4 \%$ ), and mortality in relation to

163 TSS followed the expected concentration-dependent response (Fig. S4, Supporting

164 Information). The $\mathrm{LC}_{50}$ values in the treatments with 20-100 \% MP were significantly lower

165 than in the $100 \%$ kaolin treatment, $13-43 \mathrm{mg} \mathrm{L}^{-1}$ and $482 \mathrm{mg} \mathrm{L}^{-1}$, respectively (Fig. 2), with

166 the non-overlapping confidence intervals between the treatments with pure kaolin and the

167 mixtures. The highest mortality was observed in the $80 \%$ MP treatment; however, due to the

168 broad confidence intervals for the $\mathrm{LC}_{50}$ values, particularly in the mixtures, the differences

169 across all treatments with MP were not statistically significant.

170 The one-phase exponential decay function provided an adequate fit for the relationship

171 between the $\mathrm{LC}$ values and the \%MP in the mixture $\left(\mathrm{LC}_{50}: \mathrm{R}^{2}=0.95\right.$ and $\left.\mathrm{LC}_{10}: \mathrm{R}^{2}=0.99\right)$.

172 The curves suggested that at \%MP exceeding $40 \%$, the LC values levelled off at 18 and $2 \mathrm{mg}$

$173 \mathrm{~L}^{-1}$ for $\mathrm{LC}_{50}$ and $\mathrm{LC}_{10}$, respectively. The fit for the $\mathrm{LC}_{10}$ values was used to derive the \% $\mathrm{MP}$

174 threshold (NOE\%MP) above which significantly higher mortality was observed. This value

175 was determined as $1 \% \mathrm{MP}$ in the mixture with $36 \mathrm{mg} \mathrm{L}^{-1} \mathrm{TSS}$. 


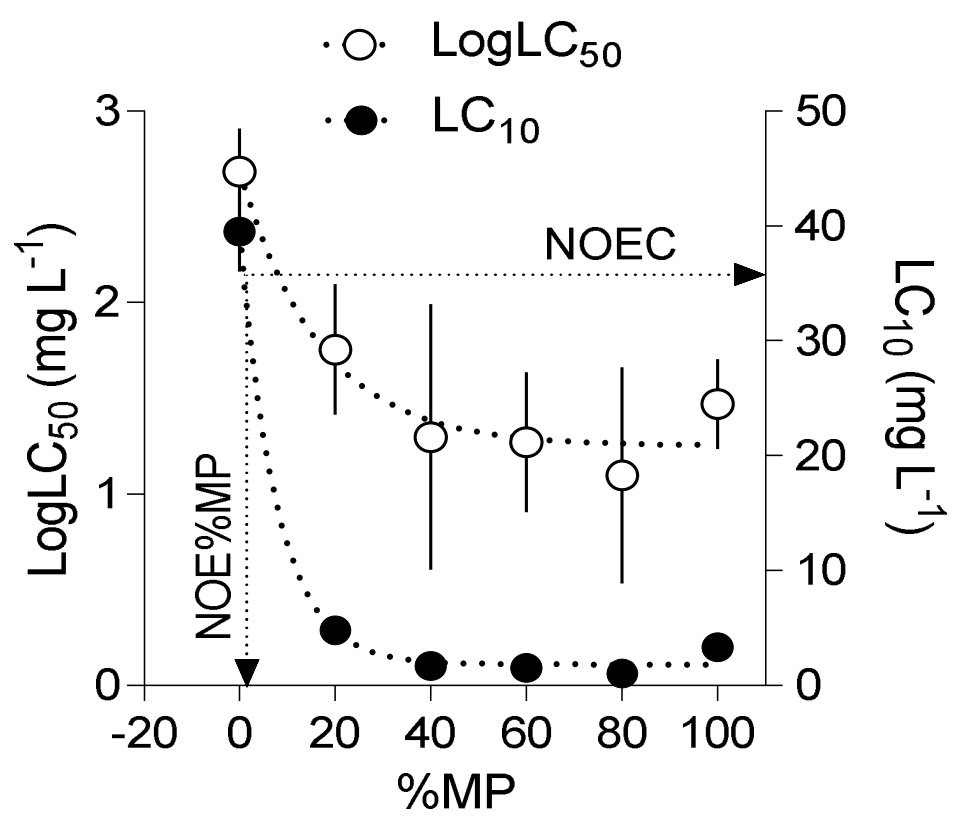

176

177 Figure 2. Relationships between the estimated $\operatorname{LogLC} \mathrm{C}_{50}$ values (mean and $95 \%$ confidence

178 interval; left $\mathrm{Y}$-axis) and the corresponding $\mathrm{LC}_{10}$ values (right $\mathrm{Y}$-axis) for D. magna and the

179 mass contribution of MP (\%MP, $0 \%$ to $100 \%)$ in the test mixtures of MP and kaolin. One-

180 phase exponential decay was used to find the $\mathrm{LC}_{10}$ for the MP-kaolin mixture corresponding

181 to the lower bound of the confidence interval for the kaolin treatment (NOEC) and the

182 NOE\%MP representing no effect level of \%MP in the test system. 
DISCUSSION

\section{Test performance}

186 Using the MP Ratio Test, we delineated effects of MP from those of inorganic particles of

187 similar size and shape in the mixtures mimicking natural suspended solids in the aquatic environment. Moreover, the test design allowed estimating critical levels for the suspended MP that can be considered as hazardous. The hazardous level of MP contribution to TSS is an important outcome of our test approach because the effects of particulate contaminants, such as MP, depend not only on the absolute concentration but also on their relative contribution to

192 the suspended matter or sediment; the latter was also recently shown by Redondo-

193 Hasselerharm and co-workers. ${ }^{39}$

194 Ecotoxicological data describing effect thresholds in ecologically meaningful settings are needed in microplastic research to support the hazard assessment of solid polymer particles. The MP Ratio Test can be used as a tool for screening a variety of polymer materials and

197 particle types as well as for selecting suitable test organisms and endpoints. It is conceptually

198 similar to both the already standard bioassay approach for testing toxic effluents and

199 sediments by serial dilutions ${ }^{40}$ and evaluating algal toxicity in mixtures with varying

200 proportion of the test species. ${ }^{41}$ Furthermore, the need for well-characterised reference materials when evaluating, for example, particle size effects, is also recognised in nanomaterial toxicity assessment. ${ }^{42,43}$ However, to our knowledge, our study is the first to assess the effects of suspended MP in mixtures with natural particles using a dose-response 204 approach. 
207 We found PET MP to be more hazardous than kaolin for D. magna. The addition of PET

208 powder to the kaolin suspension increased Daphnia mortality, with $\mathrm{LC}_{50}$ values dropping

209 more than 8 -fold in mixtures with $>20 \%$ of MP. Moreover, TSS containing $1 \%$ PET was

210 predicted to have significantly lower $\mathrm{LC}_{10}$ than pure kaolin suspension. The corresponding

211 concentration for $1 \%$ PET-kaolin mixture was $36 \mathrm{mg} \mathrm{L}^{-1}$, which would represent NOEC of

212 TSS containing plastics (Fig. 2).

213 The reported effect concentrations of MP are highly variable and span orders of magnitude

214 even within the same level of biological organisation. ${ }^{27}$ Unfortunately, only a few reports

215 provide dose-response data for MP-exposed microcrustaceans, ${ }^{33,37,44}$ and reference particles

216 are rarely employed. ${ }^{13,33}$ Although truly comparable published data on PET toxicity for

217 daphnids are not available; some reports are still relevant. For example, a 6-day static

218 exposure of the copepod Parvocalanus crassirostris to $14 \mathrm{mg} \mathrm{L}^{-1}$ of PET $(<11 \mu \mathrm{m}$; assuming

219 that particles are $10-\mu \mathrm{m}$ and spherical, with a density of $1.38 \mathrm{~g} \mathrm{~cm}^{3}$ ) was found to decrease

220 population size. ${ }^{45}$ This concentration is four times higher compared our $\mathrm{LC}_{10}$ for $100 \% \mathrm{MP}$.

221 The difference, at least partially, can be explained by the fact that our animals were starved

222 during the exposure. Moreover, the suspended amount of PET in the study with $P$.

223 crassirostris ${ }^{45}$ is uncertain, because of the static exposure and the lack of information on the

224 MP mass in the system. For other planktonic filter-feeders and various MP, the reported $\mathrm{LC}_{50}$

225 values are similar to what we have found for PET using the MP Ratio Test. For example, a

226 96-h $\mathrm{LC}_{50}$ of $57.43 \mathrm{mg} \mathrm{L}^{-1}$ was reported for $D$. magna neonates exposed to $1-\mu \mathrm{m}$

227 polyethylene (PE) particles, although some mortality was observed already at $12.5 \mathrm{mg} \mathrm{L}^{-1} \cdot 37$

228 Also with D. magna, exposure to PE fragments $(10-75 \mu \mathrm{m})$ produced a $48-\mathrm{h} \mathrm{LC}_{50}$ of $65 \mathrm{mg}$

$229 \mathrm{~L}^{-1}{ }^{44}$ These findings are comparable with the $96-\mathrm{h} \mathrm{LC}_{50}$ observed in the $100 \% \mathrm{MP}$ treatment

$230\left(30 \mathrm{mg} \mathrm{L}^{-1}\right)$ as well as in the mixtures (13-43 $\left.\mathrm{mg} \mathrm{L}^{-1}\right)$, although our values are consistently

231 lower, which could be related to possible variations in MP aggregation and settling during the 
232 exposure as well as in specific properties of polymers and particle size. ${ }^{46}$ The differences in

233 the experimental setup highlight the importance of both particle characterisation in MP

234 research ${ }^{28}$ and keeping the test particle in suspension when using pelagic feeders. Still, based

235 on either modelled data or some of the highest levels reported in the ocean, ${ }^{7,47}$ the levels of

236 MP accessible for zooplankton in nature are much - approximately two to four orders of

237 magnitude - lower than the experimentally determined MP levels for the observed effects.

\section{Important issues in experimental design}

240 The straightforward logistics of our approach makes it possible to examine a large number of 241 treatments (e.g., TSS concentrations, plastic material, particle size and shape) with reasonable 242 effort. When testing the PET effects on the daphnid survivorship, one person was able to 243 handle 50 experimental units per day routinely. Further developments should include a higher 244 number of treatments with lower \%MP to provide more ecologically meaningful test 245 suspensions and improve the threshold estimates for the hazardous MP levels. Furthermore, 246 when more information of the environmentally realistic exposure becomes available, future 247 experimental designs can focus on narrowing concentration ranges, as well as including 248 endpoints that are more sensitive. When testing PET, for example, a higher resolution of the $249 \% \mathrm{MP}$ at the lower range $(<20 \%)$ would have provided a more precise estimate of NOEC and

250 the corresponding \%MP in the mixture. Also, various reference particles can be used

251 depending on the research context, both natural and anthropogenic.

252 The selection of the reference particles is not a trivial task. One possible criterion is size

253 because size spectra for MP and many naturally occurring particles overlap (clay: <2 $\mu \mathrm{m}$, silt:

$2542-50 \mu \mathrm{m}$, and sand: $50 \mu \mathrm{m}-2 \mathrm{~mm}) .{ }^{48}$ Another recently advocated option is to benchmark the 255 test particles to the reference MP using reference plastics supplied by commercial vendors, ${ }^{28}$ 
256 which have a narrow size range and reliable certificates of analysis. Such reference materials

257 would add credibility to any adverse effects exerted by unknown materials. Here, we used

258 kaolin, because it has been relatively well studied in hazard assessment of suspended solids. ${ }^{49}$

259 Several studies also suggest its low toxicity for daphnids, ${ }^{13,50}$ which was supported by our $96-$

$260 \mathrm{~h} \mathrm{LC}_{50}$ of $482 \mathrm{mg} \mathrm{L}^{-1}$. However, in chronic tests with $D$. magna, Robinson and colleagues

261 observed a 7-d LC 50 of $74.5 \mathrm{mg} \mathrm{L}^{-1},{ }^{32}$ which can be related to both delayed effects and

262 possible difference in kaolin composition and aggregation during the test. Kaolin powder is a

263 commercially available standard product, but depending on the vendor, it might contain

264 impurities and vary in particle size distribution.

265 When testing effects of suspensions on planktonic organisms, it is essential to prevent that

266 particles sediment or float, because it will affect the encounter rate and intake by the animals.

267 Moreover, particles with different specific gravity will settle with different rates; hence

268 performing tests under static conditions would not provide stable exposure levels. The

269 exposure of planktonic organisms should preferably be conducted using a plankton wheel that

270 keeps particles in suspension, thus, ensuring stable exposure conditions. ${ }^{51,52}$ In plankton

271 ecology, the use of a plankton wheel is a standard procedure when conducting grazing

272 experiments because it minimises the sedimentation of algae. Although less common in

273 ecotoxicological testing, the plankton wheel has been used to assess the effects of suspended

274 clay and other particulate materials on planktonic filtrators. ${ }^{53}$ Even though this method

275 requires some additional effort compared to static exposures commonly employed in OECD-

276 tests for soluble chemicals, it is a necessity for standardising the exposure conditions.

277 Another area of concern with respect to the standardisation of the testing procedure is particle

278 behaviour, such as aggregation and settling, during the exposure. Since suspended particles

279 may have complex behaviour, their dispersion stability during exposure should be controlled.

280 The extent of aggregation, i.e., aggregate size, composition and cohesion, is dependent on the 
281 complex interplay between various components, such as particle material, size, concentration,

282 media ion composition, and organic material present. Aggregation may have affected the

283 amount and size spectra of PET and kaolin and could potentially explain the non-linear

284 response of LC to \%MP. The relationship between the aggregate formation and the measured

285 response is particularly relevant at high TSS concentrations. On the other hand, aggregation,

286 at least to some extent, is preventable by, for example, dispersants and sonication, which may

287 be sufficient in short-term experiments. These methods are employed in nanomaterial effect

288 assessments $^{42}$ and, in some cases, microplastic studies. ${ }^{54}$

289 The exposure duration is yet another issue that needs to be considered in acute tests. Daphnid

290 energy expenditure may increase in the presence of non-food particles since the induced

291 filtering activity is similar as for food particles, ${ }^{55}$ while the cost of cleaning appendages and

292 egestion through postabdominal rejections increase. ${ }^{15}$ Sensitivity to the refractory material

293 would increase with starvation, and the higher energy expenditure may decrease survival. In

294 D. magna neonates, the critical exposure time is $96 \mathrm{~h}$, which marks the depletion of their fat

295 reserves. ${ }^{56}$ Earlier studies using the D. magna acute immobilisation test for particle

296 suspensions have also shown that it is suitable to extend the exposure period to $96 \mathrm{~h}$ from the

297 standard $48 \mathrm{~h}$ to increase the sensitivity of the test. ${ }^{37}$ However, if a test organism other than

298 Daphnia neonates is used, the duration of the exposure must be adjusted depending on its

299 capacity to withstand starvation.

\section{Implications for regulatory measures and concluding remarks}

302 Many suspension- and filter-feeders frequently face turbid environments with high

303 concentrations of refractory materials generated by natural processes, such as terrestrial

304 runoff, currents, and weather-induced bottom sediment resuspension, ${ }^{57}$ but also by 
305 anthropogenic activities, such as dredging and capping of contaminated sediments using

306 various materials. In aquatic ecology, conditions with elevated TSS are acknowledged as

307 stressful $^{58}$ and regulated by water quality standards..$^{24,59}$ The quality standards vary across

308 regions and types of aquatic systems, e.g., lotic and lentic, and systems with different natural

309 levels of suspended solids. For example, the Alaskan state standard for clear-water lakes is a

310 maximum increase of TSS, above background levels, equivalent to $25 \mathrm{mg} \mathrm{L}^{-1}$, whereas an

311 increase of $100 \mathrm{mg} \mathrm{L}^{-1}$ is acceptable for streams. ${ }^{25}$ Similarly, hazard assessment of MP in

312 different systems would eventually require that effect-thresholds are established for the

313 critical MP concentration, such as NOE\%MP, relative to the background TSS levels and their

314 combined interactions with biota.

315 By using reference particles - natural minerals or standardised plastics - with predictable

316 effects on the test organisms, one may identify and account for the general responses

317 anticipated from exposure to suspended solids. The relative importance of MP addition to the

318 suspension could thereby be assessed. Interestingly, the hazard level we found for MP

319 contribution to TSS using a planktonic organism is virtually identical to the $\mathrm{EC}_{10}$ of $1 \% \mathrm{MP}$

320 per sediment dry weight, reported for a benthic macroinvertebrate. ${ }^{39}$ This could further

321 support the possibility to benchmark MP effects against the lower $95 \%$ confidence bound of

322 the reference material and using the corresponding contribution of MP in the mixture to

323 estimate the hazard level of MP (Fig. 2).

324 The hazard assessment and the regulatory framework for MP contaminants in aquatic systems

325 require integration with an assessment of particulate matter pollution at large because the

326 approaches required to establish toxicity are similar. Moreover, raising levels of black carbon

327 in the atmosphere implies increased inputs of these particles in the aquatic systems, where

328 their environmental effects are also a matter of concern. ${ }^{60}$ Addressing all types of particulate 
329 pollution and focusing on physicochemical properties of these particles would provide a

330 translational value when developing testing and regulatory practices.

\section{ACKNOWLEDGEMENT}

333 This research was funded by projects WEATHER-MIC, irPLAST and MICROPOLL, which

334 are supported through the Joint Programming Initiative Healthy and Productive Seas and

335 Oceans (JPI-Oceans), Swedish Research Council for Environment, Agricultural Sciences and

336 Spatial Planning (FORMAS), the joint Baltic Sea research and development programme

337 (BONUS) and the Swedish Innovation Agency VINNOVA.

338 Supporting Information. Additional text and four figures describing particle preparation

339 and size distributions analyses, confirmed particle ingestion and separate dose-response

340 curves for all the tested mixtures of and kaolin and PET. 


\section{REFERENCES}

(1) Imhof, H. K.; Ivleva, N. P.; Schmid, J.; Niessner, R.; Laforsch, C. Contamination of Beach Sediments of a Subalpine Lake with Microplastic Particles. Curr. Biol. 2013, 23 (19), R867R868.

(2) Hurley, R.; Woodward, J.; Rothwell, J. J. Microplastic Contamination of River Beds Significantly Reduced by Catchment-Wide Flooding. Nat. Geosci. 2018, 11 (4), 251-257.

(3) Cózar, A.; Echevarría, F.; González-Gordillo, J. I.; Irigoien, X.; Úbeda, B.; Hernández-León, S.; Palma, Á. T.; Navarro, S.; García-de-Lomas, J.; Ruiz, A.; et al. Plastic Debris in the Open Ocean. Proc. Natl. Acad. Sci. 2014, 111 (28), 10239-10244.

(4) Peeken, I.; Primpke, S.; Beyer, B.; Gütermann, J.; Katlein, C.; Krumpen, T.; Bergmann, M.; Hehemann, L.; Gerdts, G. Arctic Sea Ice Is an Important Temporal Sink and Means of Transport for Microplastic. Nat. Commun. 2018, 9 (1), 1505.

(5) Jambeck, J. R.; Geyer, R.; Wilcox, C.; Siegler, T. R.; Perryman, M.; Andrady, A.; Narayan, R.; Law, K. L. Plastic Waste Inputs from Land into the Ocean. Science 2015, 347 (6223), 768771.

(6) Backhaus, T.; Wagner, M. Microplastics in the Environment: Much Ado about Nothing? A Debate; e26507v1; PeerJ Preprints, 2018.

(7) Lenz, R.; Enders, K.; Nielsen, T. G. Microplastic Exposure Studies Should Be Environmentally Realistic. Proc. Natl. Acad. Sci. 2016, 201606615.

(8) Burton, G. A. Stressor Exposures Determine Risk: So, Why Do Fellow Scientists Continue To Focus on Superficial Microplastics Risk? Environ. Sci. Technol. 2017, 51 (23), 13515-13516.

(9) Hale, R. C. Are the Risks from Microplastics Truly Trivial? Environ. Sci. Technol. 2018, 52 (3), 931-931.

(10) Wegner, A.; Besseling, E.; Foekema, E. m.; Kamermans, P.; Koelmans, A. a. Effects of Nanopolystyrene on the Feeding Behavior of the Blue Mussel (Mytilus Edulis L.). Environ. Toxicol. Chem. 2012, 31 (11), 2490-2497. 
(11) Cole, M.; Galloway, T. S. Ingestion of Nanoplastics and Microplastics by Pacific Oyster Larvae. Environ. Sci. Technol. 2015, 49 (24), 14625-14632.

(12) Sussarellu, R.; Suquet, M.; Thomas, Y.; Lambert, C.; Fabioux, C.; Pernet, M. E. J.; Le Goïc, N.; Quillien, V.; Mingant, C.; Epelboin, Y.; et al. Oyster Reproduction Is Affected by Exposure to Polystyrene Microplastics. Proc. Natl. Acad. Sci. U. S. A. 2016, 113 (9), 24302435.

(13) Ogonowski, M.; Schür, C.; Jarsén, Å.; Gorokhova, E. The Effects of Natural and Anthropogenic Microparticles on Individual Fitness in Daphnia magna. PLOS ONE 2016, 11 (5), e0155063.

(14) Cole, M.; Lindeque, P.; Fileman, E.; Halsband, C.; Galloway, T. S. The Impact of Polystyrene Microplastics on Feeding, Function and Fecundity in the Marine Copepod Calanus helgolandicus. Environ. Sci. Technol. 2015, 49 (2), 1130-1137.

(15) Kirk, K. L. Effects of Suspended Clay on Daphnia Body Growth and Fitness. Freshw. Biol. 1992, $28(1), 103-109$.

(16) Kirk, K. L. Suspended Clay Reduces Daphnia Feeding Rate. Freshw. Biol. 1991, 25 (2), 357365.

(17) Cranford, P. J.; Gordon, D. C. The Influence of Dilute Clay Suspensions on Sea Scallop (Placopecten Magellanicus) Feeding Activity and Tissue Growth. Neth. J. Sea Res. 1992, 30, 107-120.

(18) Wilson, W. J. The Effects of Concentration and Particle Size of Suspended Materials on Growth and Condition of the Pacific Oyster (Crassostrea Gigas). 1973.

(19) Kaposi, K. L.; Mos, B.; Kelaher, B. P.; Dworjanyn, S. A. Ingestion of Microplastic Has Limited Impact on a Marine Larva. Environ. Sci. Technol. 2014, 48 (3), 1638-1645.

(20) Martínez-Gómez, C.; León, V. M.; Calles, S.; Gomáriz-Olcina, M.; Vethaak, A. D. The Adverse Effects of Virgin Microplastics on the Fertilization and Larval Development of Sea Urchins. Mar. Environ. Res. 2017.

(21) Lloyd, D. S. Turbidity as a Water Quality Standard for Salmonid Habitats in Alaska. North Am. J. Fish. Manag. 1987, 7 (1), 34-45. 
(22) McCabe, G. D.; O'Brien, W. J. The Effects of Suspended Silt on Feeding and Reproduction of Daphnia pulex. Am. Midl. Nat. 1983, 110 (2), 324-337.

(23) Robertson, M. J.; Scruton, D. A.; Clarke, K. D. Seasonal Effects of Suspended Sediment on the Behavior of Juvenile Atlantic Salmon. Trans. Am. Fish. Soc. 2007, 136 (3), 822-828.

(24) Multi-Sector General Permit for Stormwater Discharges Associated with Industrial Activity (MSGP). United States Environmental Protection Agency (EPA), National Pollutant Discharge Elimination System (NPDES) April 6, 2015.

(25) Lloyd, D. S. Turbidity in Freshwater Habitats of Alaska - a Review of Published and Unpublished Literature Relevant to the Use of Turbidity as a Water Quality Standard; 85-1; Alaska Department of Fish and Game - Habitat Division, 1985.

(26) Gerritsen, J.; Porter, K. G. The Role of Surface Chemistry in Filter Feeding by Zooplankton. Science 1982, 216 (4551), 1225-1227.

(27) Ogonowski, M.; Gerdes, Z.; Gorokhova, E. What We Know and What We Think We Know about Microplastic Effects - A Critical Perspective. Curr. Opin. Environ. Sci. Health 2018, 1, $41-46$.

(28) Connors, K. A.; Dyer, S. D.; Belanger, S. E. Advancing the Quality of Environmental Microplastic Research. Environ. Toxicol. Chem. 2017, 36 (7), 1697-1703.

(29) Zhao, S.; Zhu, L.; Li, D. Microplastic in Three Urban Estuaries, China. Environ. Pollut. 2015, 206, 597-604.

(30) Cole, M.; Webb, H.; Lindeque, P. K.; Fileman, E. S.; Halsband, C.; Galloway, T. S. Isolation of Microplastics in Biota-Rich Seawater Samples and Marine Organisms. Sci. Rep. 2014, 4.

(31) Fischer, E. K.; Paglialonga, L.; Czech, E.; Tamminga, M. Microplastic Pollution in Lakes and Lake Shoreline Sediments - A Case Study on Lake Bolsena and Lake Chiusi (Central Italy). Environ. Pollut. 2016, 213, 648-657.

(32) Robinson, S. E.; Capper, N. A.; Klaine, S. J. The Effects of Continuous and Pulsed Exposures of Suspended Clay on the Survival, Growth, and Reproduction of Daphnia magna. Environ. Toxicol. Chem. 2009, 29 (1), 168-175. 
(33) Casado, M. P.; Macken, A.; Byrne, H. J. Ecotoxicological Assessment of Silica and Polystyrene Nanoparticles Assessed by a Multitrophic Test Battery. Environ. Int. 2013, 51, 97105.

(34) Rellstab, C.; Spaak, P. Starving with a Full Gut? Effect of Suspended Particles on the Fitness of Daphnia hyalina. Hydrobiologia 2007, 594 (1), 131-139.

(35) Besseling, E.; Wang, B.; Lürling, M.; Koelmans, A. A. Nanoplastic Affects Growth of S. Obliquus and Reproduction of D. Magna. Environ. Sci. Technol. 2014, 48 (20), 12336-12343.

(36) OECD. Test No. 202: Daphnia sp. Acute Immobilisation Test; Organisation for Economic Cooperation and Development: Paris, 2004.

(37) Rehse, S.; Kloas, W.; Zarfl, C. Short-Term Exposure with High Concentrations of Pristine Microplastic Particles Leads to Immobilisation of Daphnia magna. Chemosphere 2016, 153, $91-99$.

(38) Beasley, A.; Belanger, S. E.; Brill, J. L.; Otter, R. R. Evaluation and Comparison of the Relationship between NOEC and EC10 or EC20 Values in Chronic Daphnia Toxicity Testing. Environ. Toxicol. Chem. 2015, 34 (10), 2378-2384.

(39) Redondo-Hasselerharm, P. E.; Falahudin, D.; Peeters, E. T. H. M.; Koelmans, A. A. Microplastic Effect Thresholds for Freshwater Benthic Macroinvertebrates. Environ. Sci. Technol. 2018, 52 (4), 2278-2286.

(40) Ferraz, M. A.; Alves, A. V.; de Cássia Muniz, C.; Pusceddu, F. H.; Gusso-Choueri, P. K.; Santos, A. R.; Choueri, R. B. Sediment Toxicity Identification Evaluation (TIE Phases I and II) Based on Microscale Bioassays for Diagnosing Causes of Toxicity in Coastal Areas Affected by Domestic Sewage. Environ. Toxicol. Chem. 2017, 36 (7), 1820-1832.

(41) Jónasdóttir, S. H.; Kiørboe, T.; Tang, K. W.; St. John, M.; Visser, A. W.; Saiz, E.; Dam, H. G. Role of Diatoms in Copepod Production: Good, Harmless or Toxic? Mar. Ecol. Prog. Ser. 1998, $172,305-308$.

(42) Handy, R. D.; Brink, N. van den; Chappell, M.; Mühling, M.; Behra, R.; Dušinská, M.; Simpson, P.; Ahtiainen, J.; Jha, A. N.; Seiter, J.; et al. Practical Considerations for Conducting 
Ecotoxicity Test Methods with Manufactured Nanomaterials: What Have We Learnt so Far? Ecotoxicology 2012, 21 (4), 933-972.

(43) Stone, V.; Nowack, B.; Baun, A.; van den Brink, N.; von der Kammer, F.; Dusinska, M.;

Handy, R.; Hankin, S.; Hassellöv, M.; Joner, E.; et al. Nanomaterials for Environmental Studies: Classification, Reference Material Issues, and Strategies for Physico-Chemical Characterisation. Sci. Total Environ. 2010, 408 (7), 1745-1754.

(44) Frydkjær, C. K.; Iversen, N.; Roslev, P. Ingestion and Egestion of Microplastics by the Cladoceran Daphnia magna: Effects of Regular and Irregular Shaped Plastic and Sorbed Phenanthrene. Bull. Environ. Contam. Toxicol. 2017, 99 (6), 655-661.

(45) Heindler, F. M.; Alajmi, F.; Huerlimann, R.; Zeng, C.; Newman, S. J.; Vamvounis, G.; van Herwerden, L. Toxic Effects of Polyethylene Terephthalate Microparticles and Di(2Ethylhexyl)Phthalate on the Calanoid Copepod, Parvocalanus Crassirostris. Ecotoxicol. Environ. Saf. 2017, 141, 298-305.

(46) Rist, S.; Baun, A.; Hartmann, N. B. Ingestion of Micro- and Nanoplastics in Daphnia magna Quantification of Body Burdens and Assessment of Feeding Rates and Reproduction. Environ. Pollut. 2017, 228, 398-407.

(47) Enders, K.; Lenz, R.; Stedmon, C. A.; Nielsen, T. G. Abundance, Size and Polymer Composition of Marine Microplastics $\geq 10 \mathrm{~mm}$ in the Atlantic Ocean and Their Modelled Vertical Distribution. Mar. Pollut. Bull. 2015, 100 (1), 70-81.

(48) Handy, R. D.; Brink, N. van den; Chappell, M.; Mühling, M.; Behra, R.; Dušinská, M.; Simpson, P.; Ahtiainen, J.; Jha, A. N.; Seiter, J.; et al. Practical Considerations for Conducting Ecotoxicity Test Methods with Manufactured Nanomaterials: What Have We Learnt so Far? Ecotoxicology 2012, 21 (4), 933-972.

(49) McFarland, V. A.; Peddicord, R. K. Lethality of a Suspended Clay to a Diverse Selection of Marine and Estuarine Macrofauna. Arch. Environ. Contam. Toxicol. 1980, 9 (6), 733-741.

(50) Weltens, R.; Goossens, R.; Puymbroeck, S. V. Ecotoxicity of Contaminated Suspended Solids for Filter Feeders Daphnia magna. Arch. Environ. Contam. Toxicol. 2000, 39 (3), 315-323. 
(51) Robins, D. B.; Bellan, I. E. A Controlled-Temperature Plankton Wheel. Mar. Biol. 1986, 92 (4), 587-593.

(52) Anraku, M. Some Technical Problems Encountered in Quantitative Studies of Grazing and Predation by Marine Planktonic Copepods. J. Oceanogr. Soc. Jpn. 1964, 20 (5), 221-231.

(53) Kirk, K. L.; Gilbert, J. J. Suspended Clay and the Population Dynamics of Planktonic Rotifers and Cladocerans. Ecology 1990, 71 (5), 1741-1755.

(54) Hüffer, T.; Praetorius, A.; Wagner, S.; von der Kammer, F.; Hofmann, T. Microplastic Exposure Assessment in Aquatic Environments: Learning from Similarities and Differences to Engineered Nanoparticles. Environ. Sci. Technol. 2017, 51 (5), 2499-2507.

(55) Wiedner, C.; Vareschi, E. Evaluation of a Fluorescent Microparticle Technique for Measuring Filtering Rates of Daphnia. Hydrobiologia 1995, 302 (2), 89-96.

(56) Tessier, A. J.; Henry, L. L.; Goulden, C. E.; Durand, M. W. Starvation in Daphnia: Energy Reserves and Reproductive Allocation. Limnol. Oceanogr. 1983, 28 (4), 667-676.

(57) Gulati, R.; Demott, W. The Role of Food Quality for Zooplankton: Remarks on the State-ofthe-Art, Perspectives and Priorities. Freshw. Biol. 1997, 38 (3), 753-768.

(58) Pelletier, M.; Ho, K.; Cantwell, M.; Perron, M.; Rocha, K.; Burgess, R. M.; Johnson, R.; Perez, K.; Cardin, J.; Charpentier, M. A. Diagnosis of Potential Stressors Adversely Affecting Benthic Invertebrate Communities in Greenwich Bay, Rhode Island, USA. Environ. Toxicol. Chem. 2016, 36 (2), 449-462.

(59) Canadian Council of Ministers of the Environment. 2002. Canadian Water Quality Guidelines for the Protection of Aquatic Life: Total Particulate Matter; Canadian environmental quality guidelines; Winnipeg, 1999; pp 1-13.

(60) Shrestha, G.; Traina, S. J.; Swanston, C. W. Black Carbon's Properties and Role in the Environment: A Comprehensive Review. Sustainability 2010, 2 (1), 294-320. 